Board of Governors of the Federal Reserve System

International Finance Discussion Papers

Number 1079

April 2013

Taxation, Match Quality and Social Welfare

Brendan Epstein and Ryan Nunn

NOTE: International Finance and Discussion Papers are preliminary materials circulated to stimulate discussion and critical comment. References in publications to International Finance Discussion Papers (other than an acknowledgment that the writer has had access to unpublished material) should be cleared with the author or authors. Recent IDFPs are available on the Web at www.federalreserve.gov/pubs/ifdp/. This paper can be downloaded without charge from Social Science Research Network electronic library at www.ssrn.com. 


\title{
Taxation, Match Quality and Social Welfare*
}

\author{
Brendan Epstein ${ }^{\dagger}$ and Ryan Nunn ${ }^{\ddagger}$
}

April 19, 2013

\begin{abstract}
A large public finance literature argues that taxable income elasticities are a sufficient statistic for the social welfare consequences of taxation. We develop calibrations that show such deadweight loss calculations are overestimates proportional to the quantitative significance of heterogeneity in amenities across job matches. In particular, the endogenous supply of amenities can substantially exacerbate this overestimation in both static and dynamic environments. Given the possibility of gradual migration of workers into more amenity-focused job matches in response to tax increases, welfare calculations based on long-run taxable income elasticities can be more misleading than those based on short-run elasticities.
\end{abstract}

Keywords: taxable income elasticity, endogenous amenities, match quality, deadweight loss.

JEL codes: H21, J32, J63

${ }^{*}$ The views in this paper are solely the responsibility of the authors and should not be interpreted as reflecting the views of the Board of Governors of the Federal Reserve System, the US Treasury Department, or of any other person associated with the Federal Reserve System or US Treasury Department. The authors wish to thank Gabriel Ehrlich, Miles Kimball, Brian McCall, David Ratner, Daniel Silverman, and Mel Stephens for useful comments and discussions. All remaining errors are the authors' own.

${ }^{\dagger}$ Board of Governors of the Federal Reserve System; 20th and C Streets, NW; Washington, D.C. 20551. Email: brendan.epstein@frb.gov.

${ }^{\ddagger}$ U.S. Department of the Treasury; 1500 Pennsylvania Avenue, NW; Washington, D.C. 20220. Email: ryan.nunn@treasury.gov. 


\section{Introduction}

The relationship between taxation and social welfare is of central importance to public finance and the accurate appraisal of public policy. In a sufficiently simple model, the behavioral employment response to a tax entirely determines its associated deadweight loss (DWL), and the labor supply elasticity is sufficient for its calculation. However, as argued in Feldstein (1999), behavioral responses alone do not incorporate some important channels by which taxes reduce social welfare. The taxable income elasticity, rather, reflects information concerning tax evasion, shifts to deductible and tax-excluded consumption, and so forth, all of which affect deadweight loss. Recent literature has developed around the proposition (described in Chetty, 2008) that taxable income elasticities can serve as a sufficient statistic for the deadweight loss from taxation, assuming the absence of fiscal and classical externalities. This notion is refined by the work in Nunn (2012), which suggests that social welfare inference from any observed elasticity is incorrect if quantitativelysignificant job amenities are ignored by the econometrician. Nunn estimates a labor search model with exogenously-endowed match-specific amenities, shows that non-wage amenities are an important component of worker compensation, and demonstrates that their existence induces the over-estimation of DWL from taxation. ${ }^{1}$

The aim of the present paper is to develop a broader exploration of match amenities and their connection to social welfare. In particular, we complement the literature by focusing on the welfare impact of amenities when their production is endogenous. Our analysis shows that, compared to cases in which amenities are mistakenly ignored, their supply is incorrectly taken as exogenous, or their production process is misspecified, endogenous amenity supply is consistent with increased overestimation of the deadweight loss from taxation. Moreover, we show that welfare calculations based on long-run taxable income elasticities can be relatively misleading compared to those based on short-run taxable income elasticities.

Overestimation of deadweight loss proceeds from worker flows to higher-amenity matches and is exacerbated by the endogenous supply of amenities by firms. Suppose that the wage tax rate increases unexpectedly. Worker flows to higher-amenity matches result in gradually diminishing observed wages, as workers find their way to tax-preferred matches (e.g., reduced commute time

\footnotetext{
${ }^{1}$ See Epstein and Kimball (2011) for related research on the role of on-the-job utility, amenities, welfare, and the long-run behavior of work hours.
} 
but lower salary). At the same time, firms respond to a tax increase by immediately raising their provision of match amenities (e.g., more flexible work hours or more interesting tasks), effectively shifting compensation from the tax-disadvantaged wage into the tax-preferred amenity. An econometrician may mistake these shifts for behavioral labor supply responses, which overstates their welfare impact.

This paper proceeds as follows. In Section 2, we develop our baseline model, which provides an environment with search frictions and allows for empirical estimation. In particular, the introduction of search frictions enables the coexistence of matches of varying quality and amenity productivity and the opportunity for workers to move between these matches. The model accounts for match-specific job quality as well as the endogenous provision of amenities given convex production costs. As detailed in Section 3, following Nunn (2012) we estimate the model with duration data from the 1979 National Longitudinal Survey of Youth (NLSY79).

In Section 4.1, we compute steady state equilibria for various tax rates and show that, when amenities are mistakenly ignored, the flexible-amenity model implies a more severe overestimation of the deadweight loss from taxation relative to the case of exogenous amenity provision. As such, the problem of reliance on taxable income elasticities as a proxy for the welfare effects of taxation is exacerbated. In addition, we examine the dynamic effect of a change in taxes. The context of endogenous amenity provision allows for both instantaneous and drawn-out responses to changes in market conditions. Firms can adjust amenity supply and workers can slowly move, in accordance with their optimization problem, to matches with more efficient amenity production. Given this, we show that taxable income elasticities over-estimate deadweight loss by an even greater amount as they become more long-run in scope.

Then, in Section 4.2 we consider the impact of endogenous amenity provision within a static environment and under different utility and production-cost specifications. We find results generally akin to those in Section 4.1. This implies that the relevance of properly accounting for endogenous amenity provision for the correct estimation of DWL is not dependent on the framework of choice, be that static or dynamic.

Importantly, our static analysis serves to distinguish the impact of search and matching frictions from that of endogenous convex amenity production costs in generating results that contrast with those stemming from the Feldstein (1999) static framework with fixed linear amenity costs. 
Whether amenities are endogenous or not, search and matching frictions on their own (as in Nunn (2012)) render the assumption of linear amenity costs invalid, as workers find it impossible to instantaneously shift consumption into amenities at a constant marginal cost. In a static framework, however, linear amenity costs are indeed consistent with constant compensation tradeoffs, implying that the level of amenity provision is irrelevant for the DWL from taxation and consequently for its estimation. However, the existence of endogenous, convex amenity costs imply that in either a static or dynamic framework, the level of amenity provision is a direct factor influencing relative compensation tradeoffs. Incorrect knowledge of amenity provision can bias estimates of deadweight loss from taxation.

We close this paper as follows. Section 5 discusses previous literature. Section 6 concludes.

\section{Baseline Model}

The model we focus on builds, in particular, on those developed in Mortensen and Pissarides (1994) and Shimer (2006). Within this context, search frictions result in workers and firms meeting each other only occasionally. We account for on-the-job search, match quality heterogeneity, endogenous job separations stemming from both job-to-job transitions and changes in the idiosyncratic productivity of a match, and job switching costs.

Matches produce a flow surplus that depends on idiosyncratic, time-varying productivity $x$, a time-invariant, match-specific monetary productivity $\pi$, and an amenity $q$ that is produced by firms and chosen endogenously. The production function for the amenity is $q=q(k ; A)$, where $k$ is the capital input and $A$ is the match-specific productivity of amenity supply. Furthermore, $q^{\prime}>0$ and $q^{\prime \prime}<0$. We assume that $A$ is distributed lognormally with variance $\sigma=\sigma_{A}$ and mean $\mu=0$. Because matching opportunities are scarce and positive surplus is generated by successful matches, wages are set by bargaining over this surplus.

The model timing is as follows. A period begins with any particular worker being either unemployed or employed. A worker-firm match is characterized by both a constant match productivity $\pi$ and a constant amenity production parameter $A$. These are drawn simultaneously and do not change over the course of a successful match. ${ }^{2}$ Then, a time-varying idiosyncratic productivity

\footnotetext{
${ }^{2}$ Additional details about draws of $\pi, x, A$, and consequent amenity production, $q$, will be provided throughout the rest of this section.
} 
shock $x$ is drawn, which occurs every period. Employed individuals receive a wage and unemployed individuals receive exogenous unemployment flow benefits. ${ }^{3}$

Next, an exogenous separation shock may occur. If it does, the match is destroyed and the nowunemployed worker does not receive an employment offer until at least the subsequent period. If a separation does not occur, or if the worker was already unemployed, then a job-finding shock may occur. Firms and workers meet each other with a probability that depends only on the worker's employment status: $\alpha_{0}$ for an unemployed worker and $\alpha_{1}$ for an employed worker.

If a match shock $\alpha$ arrives, then it occurs simultaneously with the idiosyncratic productivity draw $x$, thus allowing a worker to choose between unemployment and employment (the former being chosen if the productivity draw is such that the value of unemployment is higher), switching to a new job (occurring, for employed workers, if the surplus of the new match exceeds that of the present match, in which case switching costs are paid immediately), and remaining in the old job (which occurs if an individual is already employed and the continuation value of the match exceeds that of all other alternatives). All job-finding shocks are characterized by a match quality draw and a new idiosyncratic productivity draw on which wages are based. If no match shock $\alpha$ arrives, it is still the case that an idiosyncratic draw $x$ is realized, allowing the worker to choose between continued employment at the new wage or unemployment. Following this, the economy moves into the new state and the period ends. Note that the switching cost is considered to be a sunk cost for wage-setting purposes.

Idiosyncratic productivity draws are match-specific and time-varying, so it is possible for workers to switch to lower match quality jobs $m$ with sufficiently high productivity draws $x$. $x$ is drawn from a lognormal distribution with a persistence parameter $\rho_{x}$, following the process $\log \left(x^{\prime}\right)=$ $\rho_{x} \log (x)+\epsilon_{x}$, where $\epsilon_{x} \sim N\left(0, \sigma_{x}^{2}\right) .{ }^{4}$

Match quality $m$ consists of two components: a monetary productivity term $\pi$ that accrues to the firm and a non-monetary benefits term $q$ that is entirely consumed by the worker. ${ }^{5}$ The amenity $q$ is produced endogenously by firms given the process described previously. $\pi$ draws are distributed according to a normal cdf $\Pi$ with mean zero and standard deviation $\sigma_{\pi} . m$ is equal to the sum of

\footnotetext{
${ }^{3}$ Wages are negotiated via Nash bargaining, and thus fully flexible and instantly renegotiable, with no commitment to a future path of wages.

${ }^{4}$ The $x$ grid and discrete transition matrix are formed according to the Tauchen (1986) procedure.

${ }^{5}$ Though this paper is concerned with both the distribution of match quality draws and the actual distribution of accepted draws, "match quality distribution" refers to the former, unless otherwise specified.
} 
$\pi$ and $q$ and obeys a normal cdf $M$ with mean zero and standard deviation $\sigma_{m}=\sqrt{\sigma_{\pi}^{2}+\sigma_{q}^{2}} \cdot{ }^{6}$ A one-time switching cost $c$ is incurred by employed workers who accept new job offers.

Denote a worker's value of employment by $W$, and her value of unemployment by $U$. Employed individuals receive as compensation the amenity level $q$, and also the pre-tax wage $w$ (to which a linear tax rate $\tau$ is applied). All economic agents discount the future at rate $\beta$. With probability $s$, the match is destroyed and the worker is forced into unemployment. With probability $\alpha_{1}$, the worker encounters an outside job opportunity. Thus, with probability $(1-s) \alpha_{1}$, an employed individual must decide whether to switch jobs (taking account of instantaneous job-changing costs $c$, which are time invariant and exogenous), remain in her current job, or transition into unemployment (voluntarily, if the value of doing so is greater than that of the alternatives). Similarly, with the product of the probabilities $(1-s)$ and $\left(1-\alpha_{1}\right)$, the worker must decide between remaining in her current job or transitioning into unemployment. Therefore,

$$
\begin{aligned}
W(\pi, A, x) & =(1-\tau) w(\pi, A, x)+q+\beta s U+\underbrace{\beta(1-s)\left(1-\alpha_{1}\right) \operatorname{Prob}\left(\left(U>W\left(\pi, A, x^{\prime}\right)\right) \mid x\right) \cdot U}_{\text {bad } x \text { shock: separate }} \\
& +\underbrace{\beta(1-s)\left(1-\alpha_{1}\right) \mathbb{E}\left[\mathbb{1}\left(W\left(\pi, A, x^{\prime}\right) \geq U\right) \cdot W\left(\pi, A, x^{\prime}\right)\right]}_{\text {no job offer: stay in job }} \\
& +\underbrace{\beta(1-s) \alpha_{1} \mathbb{E}\left[\max \left\{W\left(\pi^{\prime}, A^{\prime}, x_{n j}^{\prime}\right)-c, W\left(\pi, A, x^{\prime}\right), U\right\}\right]}_{\text {continuation value conditional on new job offer }},
\end{aligned}
$$

where an apostrophe denotes the value of a variable in the following period, and therefore $x_{n j}^{\prime}$ is the idiosyncratic shock associated with a new job offer. Following similar considerations,

$$
U=b+\beta\left(1-\alpha_{0}\right) U+\beta \alpha_{0} \mathbb{E}\left[W\left(\pi^{\prime}, A^{\prime}, x^{\prime}\right), U\right]
$$

where $b$ is the constant unemployment flow benefit (assumed to be financed from a lump-sum tax) and $\alpha_{0}$ is the probability an unemployed individual meets a firm. As noted above, not all meetings between firms and workers lead to a match being formed. This allows, for instance, a distinction to be made between a worker's probability of receiving a job offer and the probability of

\footnotetext{
${ }^{6} q$ is distributed normally in equilibrium because $A$ is assumed lognormal; the solution of the firm's problem in choosing $q$ (shown later) will make this evident.
} 
a transition from unemployment to employment. In the absence of this distinction, endogeneity in the acceptance of offers would potentially bias estimation of the match quality offer distribution.

Since job separations due to bad idiosyncratic draws are bilateral in the sense that an employer sees it fit to end a match under the same circumstances as a worker, the firm's value of a job, $J$, can largely be written in terms of worker value functions. In particular,

$$
\begin{aligned}
& J(\pi, A, x)=x+\pi-w(\pi, q, x)-\phi(q)+\beta(1-s)\left(1-\alpha_{1}\right) \mathbb{E}\left[\mathbb{1}\left(W\left(\pi, A, x^{\prime}\right) \geq U\right) \cdot J\left(\pi, A, x^{\prime}\right)\right] \\
& +\beta(1-s) \alpha_{1} \mathbb{E}\left[\mathbb{1}\left(\left(W\left(\pi^{\prime}, A^{\prime}, x_{n j}^{\prime}\right)-c<W\left(\pi, A, x^{\prime}\right)\right) \cap\left(W\left(\pi, A, x^{\prime}\right) \geq U\right)\right) \cdot J\left(\pi, A, x^{\prime}\right)\right],
\end{aligned}
$$

where $\phi$ is the cost function associated with amenity supply, which satisfies $\phi^{\prime}>0$ and $\phi^{\prime \prime}>0$. Note that although we do not model vacancies explicitly, following related literature, the firm's value of a job reflects free entry into vacancy creation, meaning that the value of a vacancy is zero.

The surplus from a match is given by

$$
S(\pi, A, x)=W(\pi, A, x)-U+J(\pi, A, x) .
$$

Nash bargaining over the surplus, with no commitment to a future path of wages, implies that

$$
\eta J(\pi, A, x)=(1-\eta)(1+\tau)(W(\pi, A, x)-U)
$$

where $\eta \in(0,1)$ is the bargaining power of workers. Thus, a worker's capital gain from taking a job is equal to a fraction $\eta$ of the job's surplus, with analogous interpretation on the firm side. Recall that the worker receives the entire value of the amenity $q$ in addition to the after-tax wage, so total worker compensation will equal $w(\pi, q, x)+q$. Holding overall match surplus constant, Nash bargaining ensures that a higher $q$ will be accompanied by a lower $w$. Throughout, we solve for the symmetric Nash bargaining equilibrium $\eta=0.5$.

The model just described is similar to Nunn (2012), with the following important exception: while in Nunn (2012) amenities are exogenous, in the present model they are generated according to a production function, the efficiency of which is heterogenous across matches. Amenity $q$ is optimally chosen by firms to maximize the total surplus associated with a match. Note that $q$ 
solves a subproblem separable from that solved by the Nash bargain. First, $q$ is set to make a worker indifferent between having another dollar of output devoted to wage increase, and another dollar spent on the amenity, thereby maximizing both the surplus in any given period and the total surplus of a match. ${ }^{7}$ Then, the worker and firm split the total match surplus according to a Nash bargain, conditional on the particular optimal $q$. Another way to state this is as follows: when the amenity $q$ is optimally chosen, with the marginal cost of amenity production equal to the (reciprocal of the) marginal benefit of the wage, an increase in the surplus fraction accruing to workers will simply increase the wage paid.

The model is not analytically tractable, so we solve it via value function iteration on a discrete grid and simulate it at a monthly frequency. ${ }^{8}$ As shown above, a worker's values of being unemployed or employed, as well as a firm's value of employment, are represented as Bellman equations. Since these resulting functions are both monotonic and discounted, these equations are contraction mappings. ${ }^{9}$

The $\log$ specification $q(k)=\log (A \cdot k)$ and the cost function $\phi(q)=(1 / A) \exp (q)$ are chosen for computational simplicity. Since $q$ and the wage are perfect substitutes in consumption, and $\phi^{\prime \prime}(q)>0$, there is a constant, match-specific optimal level of the amenity chosen by firms (assuming for the moment that there are no taxes). The condition defining this level is

$$
\phi^{\prime}(q)=\frac{\exp (q)}{A}=\frac{\partial u / \partial w}{\partial u / \partial q}=1 \rightarrow q=\log (A) .
$$

Note that workers receive distinct draws of $\pi$ and $A$. The latter draw implies a particular optimally-chosen $q$, and the distributions of $\pi$ and $q$ conform to the distribution of $m$ assumed by the model. Though workers and firms are indifferent between drawing $\left\{\pi_{\text {low }}, q_{\text {high }}\right\}$ or $\left\{\pi_{\text {high }}, q_{\text {low }}\right\}$, where $\pi_{l o w}+q_{\text {high }}=\pi_{\text {high }}+q_{\text {low }}$, the two draws do generate distinct observed wages. The correlation between tenure and observed wage allows for separate identification of the $\pi$ and $q$ distributions. A crucial aspect of this analysis is the effect of wage taxation on amenity supply and associated social welfare. Assume that $w$ is the pre-tax wage. When a linear wage tax $\tau$ is implemented, the

\footnotetext{
${ }^{7}$ Without changes in tax rates, the amenity is optimally held constant during a match, with idiosyncratic productivity variation reflected only in wage variation. This is due to the assumption of linear utility, which substantially simplifies solution of the model by allowing $q$ to be computed separately from the wage.

${ }^{8}$ Except under very particular assumptions (e.g., Shimer, 2003) that would make identification difficult or impossible, on-the-job search and the switching cost make it impossible to find a closed-form solution to the model.

${ }^{9}$ Blackwell (1965) and Sargent (1987).
} 
first order condition and optimal amenity level are given below. The optimal $q$ is rising in the tax rate, as workers and firms shift compensation into the tax-preferred vehicle. Indeed, note that

$$
\phi^{\prime}(q)=\frac{\exp (q)}{A}=\frac{\partial u / \partial w}{\partial u / \partial q}=\frac{1}{1-\tau} \rightarrow q=\log (A)-\log (1-\tau)
$$

\section{Data}

In order to operationalize the model, data are taken from the 1979 National Longitudinal Survey of Youth. The NLSY79 is a nationally-representative panel of more than ten thousand individuals aged 14 to 22 at inception in 1979, with periodic successive surveys conducted through the present. The detailed employment, demographic, and job spell data available through the NLSY79 is necessary for this study, in particular because they allow for the calculation of tenure moments, described below. In accordance with the scope of our investigation, we drop the military and supplemental subsamples and also remove currently-enrolled high-school and college students from the sample. This leaves us with about 30,000 primary job spells. Table 1 gives summary statistics for relevant unweighted NLSY79 variables. Figure 1 shows the unweighted empirical tenure distribution.

Particularly notable is the fact that, in the data, a surprising fraction of job-to-job wage changes are negative; fully one third of such wage changes are decreases, though measurement error is almost certainly exaggerating this figure. Due to concerns about measurement error, we use only the middle 95 percentiles of the wage data, making the same adjustment in the model's simulations so that only the trimmed data is generated. This mitigates the effect of error-ridden outliers. Wages are adjusted by the CPI-U to 2010 dollars.

Data are weighted to yield a nationally-representative sample before use in the model. We use the NLS79's tenure variables corresponding to the primary jobs of respondents as well as various demographic variables that allow construction of a conditional tenure distribution. The tenure variables are constructed by the NLSY using worker-reported job start and stop dates, and are connected across waves of the survey by means of employer identification numbers. Demographic and other variables are dated to the end of each completed job spell. In addition, we set the simulated panel length equal to the average time a worker is present in the sample. This ensures that any truncation in the data (due to the requirement that spells terminate before the sample 
ends) is matched by truncation of the simulated spells. Finally, for purposes of calculating the job-to-job transition probability, we limit the sample to those who are initially working in exactly one job.

We do not use the weighted empirical moments directly. Certain observable variables - age, education, etc. - explain some variation in job duration. Ex ante variation in worker characteristics is not part of the baseline model, so we prefer to adjust the data to more closely approximate the model's assumption of ex ante identical agents. To construct the empirical tenure variables, we first run the regression:

$$
T_{i t}=X_{i t} \beta+\epsilon_{i t}
$$

where $T_{i t}$ is the tenure for a particular person's completed job spell beginning in year $t, X_{i t}$ is demographic information associated with a person in year $t$ including age, education, sex, and race. We experimented with different specifications of industry and occupation dummies, but these made little difference to the results after the demographic variables were included. The time-varying variables are taken at the end of a job spell. Since the structural model is one of homogeneous agents who differ only ex post, we then construct tenure spells that are purged of observable variation due to age and other variables. The new tenure variable is given by $\hat{T}_{i t}=\hat{\epsilon_{i t}}+\bar{X} \hat{\beta}$, where $\bar{X}$ is the vector of population means corresponding to the demographic variables. Wages are adjusted in precisely the same way.

\section{Results}

Simulated and empirical moments are presented in Table 2 (the moments and parameters identified are similar to those used in Nunn (2012)). The model generally succeeds in matching the target moments, in particular the tenure and wage-tenure correlation moments that largely determine the dispersion of match quality and the relative importance of amenity provision. One notable exception is the flow unemployment benefit, which is substantially lower than our target. This is in part due to the large inframarginal rents implied by substantial match quality variation: many workers quickly move to matches with high match quality and do not easily move back to unemployment. Consequently, this model does not generate as many "marginal" workers as the typical search and matching environment, and average flow output is skewed upwards by the very 
productive worker-firm matches.

\subsection{Endogenous amenity supply}

We now compare the deadweight loss results from Nunn (2012) with the current analysis. The previous paper assumed amenities to be constant during a match and exogenously endowed at the moment a worker meets a firm. Amenities were therefore not permitted to adjust in response to tax changes. The current paper relaxes this assumption and allows for additional important margins of adjustment that may be relevant to the social welfare and taxable income responses to tax changes.

First, it is necessary to define social welfare and taxable income. Social welfare in a period is calculated as the sum of total flow surplus minus the cost of producing amenities and switching costs

$$
\begin{aligned}
S W= & \sum_{i}^{I}\left(\mathbb{1}\left(\text { employed }_{i t}=1\right) \cdot\left(x_{i t}+\pi_{i t}+q_{i t}-\phi\left(q_{i t}\right)\right)+\mathbb{1}\left(\text { employed }_{i t}=0\right) \cdot b\right) \\
& -\sum_{i}^{I}\left(\mathbb{1}\left(\text { jobswitch }_{i t}=1\right)\right) \cdot c-T,
\end{aligned}
$$

where $\mathbb{1}\left(j_{\text {obswitch }}=1\right)$ is an indicator for whether a particular worker moves from one match to another in a given period. $T$ is a lump-sum tax levied to pay for unemployment benefits $b$, with $T=\sum_{i}^{I} \mathbb{1}\left(\right.$ employed $\left._{i t}=0\right) \cdot b$. Moreover, note that taxable income is the sum of pre-tax wages received in a particular period

$$
\sum_{i}^{I}\left(\mathbb{1}\left(\text { employed }_{i t}=1\right) \cdot\left(w_{i t}\right)\right)
$$

and job switching costs are not considered to be tax-deductible, consistent with the fact that a substantial portion of switching costs are non-monetary.

Results are shown in Table 3, where both social welfare and taxable income are normalized to 100 in the absence of taxation. ${ }^{10}$ Whether in an economy with endogenous or exogenous amenities, the elasticity of taxable income with respect to the net-of-tax rate is a poor proxy for the social welfare elasticity. This is substantially exacerbated by endogenous amenity supply. Indeed, note

\footnotetext{
${ }^{10}$ For the endogenous amenities environment, taxable income falls below zero when the tax rate rises above $70 \%$, in which case results are omitted. Recall that workers have linear utility in consumption and may be willing to choose arbitrarily low consumption values. Also, due to simulation error, taxable income elasticities are volatile; for this reason, we additionally present the levels of taxable income.
} 
that the paths of social welfare and taxable income, as the tax rate increases, differ considerably more in the case with endogenous amenity supply than in the case with amenity endowment. As an example, between tax rates of $20 \%$ and $30 \%$, the taxable income and social welfare elasticities are 0.13 and 0.07 , respectively, in the case of exogenous amenity endowment. This is in contrast to the 0.34 and 0.09 elasticities for taxable income and social welfare, respectively, in the endogenous amenity supply case. In this latter case, taxable income falls very quickly as the tax rate rises, reflecting both the immediate ability of firms to reallocate compensation into amenities and out of wages, and also the long-run ability of workers to choose firms with higher amenity productivity $A$ but lower monetary productivity $\pi$. In the case of exogenous amenities, only the long-run movement to higher-amenity jobs drives the adjustment of taxable income and social welfare.

Also, note that social welfare and taxable income elasticities are higher in the endogenous amenity environment than in the exogenous environment. This is also a reflection of the fact that, given endogenous amenities, there is an additional margin on which firms can adjust in response to a change in taxes. Intuitively, consider the subset of workers in the exogenous amenity endowment case who are in good matches that happen to be characterized by high productivity and low amenity. A sufficiently small tax increase will not destroy these matches or induce these workers to quit for matches with higher amenity levels. However, in the endogenous amenity economy, even a small tax increase will immediately cause firms to offer higher amenity levels to everyone, including the aforementioned workers. This allows for a sharper response to tax changes. Overall, the analysis shows that to the extent that firms can adjust their supply of amenities valued by workers, the issue of deadweight loss over-estimation is more serious than in Nunn (2012).

Next, we disaggregate the implied short- and long-run mechanisms of labor adjustment to tax changes, which matter directly for a subject of much research: differences between short- and long-run taxable income elasticities (Saez et al., 2009). Saez and coauthors discuss the importance of having the long-run elasticity for the purpose of estimating the total deadweight loss from an income tax, but recognize the substantial econometric difficulties implicit in calculating long-run consequences. Short-run elasticities do not reflect the costly labor market and tax adjustments that workers can make only over a substantial period of time. On the other hand, short-run elasticities overstate the true response to tax law changes when workers can shift income across time. ${ }^{11}$ Chetty

\footnotetext{
11 "...the tax reform of 1993 seems to have generated a temporary decline in top $1 \%$ incomes in 1993 and a temporary
} 
et al. (2011) develop a model in which labor supply elasticities are measured differently depending on whether the identification strategy incorporates worker search/adjustment costs. They show that macro elasticities do not get at these costs, while micro elasticities do, causing the macro estimates to be substantially larger.

The model presented in the present paper allows for a straightforward examination of the response to taxes over time. In the presence of endogenous amenities, given a change in taxes, firms can immediately adjust their idiosyncratic optimal mix of wage and amenity compensation. This is in addition to the fact that workers have the ability to adjust by searching for new matches with preferable amenity productivity. A tax reduction, for instance, will instantly cause a reduction in amenity supply, and also creates incentives for workers to search for jobs with higher overall match quality but relatively lower amenity productivity. In order to quantify these implications we conduct an experiment in which the tax rate is initially assumed to be $24.8 \%$, and then increases unexpectedly by 10 percentage points. ${ }^{12}$ Table 4 shows results. The pre-tax-change baseline is again normalized to 100. As one would expect, taxable income falls sharply just after the unexpected tax increase, reflecting the shift of compensation to (costly) match amenities. Indeed, immediately after the tax increase, taxable income falls by about one percentage point. Taxable income then falls slowly as workers gradually find new jobs with more efficient amenity supply, and associated lower wages. The total reduction in social welfare, by contrast, occurs almost entirely in the first period.

To put results from Table 4 in perspective, it is convenient to think in terms of a social planner's problem. Intuitively, the social planner would choose a lower level of amenity and higher wage than workers and firms find it privately optimal to select in the aftermath of a tax increase, which is reflected in the initial social welfare drop. This is simply the usual logic of a social planner preferring a muted behavioral response to taxation. Perhaps counter-intuitively, however, social welfare remains roughly constant, after its initial sharp decline, as workers make their way to matches with more efficient amenity production but lower wages. While distorting in its own right, the migration of workers to these new jobs mitigates the distortion associated with the initial sharp spike in 1992 as tax filers tried to pull reported taxable income from 1993 into 1992 to take advantage of the lower 1992 tax rate. As a result, the elasticity estimated using only the years 1992 and 1993 is large." (p.28, Saez et al. (2009))

${ }^{12} 24.8 \%$ is the 2010 ratio of tax revenues (at all levels of government) to gross domestic product as estimated in the OECD Revenue Statistics. 
increase in amenity production. Thus, taxable income elasticities actually over-estimate deadweight loss more as they become more long-run in scope. Nunn (2012) explains that the existence of unobserved amenities, in a search context, are already sufficient to bias upwards estimates of deadweight loss from taxable income elasticities. The current analysis indicates that this problem is compounded by a focus on long-run elasticities, simply because these larger long-run taxable income elasticities indicate an excessively large deadweight loss. However, work that does take amenities into account would ideally use long-run elasticities, since short-run responses fail to account for endogenous changes in amenity compensation.

\subsection{Static Model}

In the previous section, we highlighted the relevance of endogenous amenity provision given convex costs for the correct estimation of the deadweight loss from taxation, as well as important differences that emerge relative to the case of exogenous amenity supply studied in Nunn (2012). In this section, we further complement the analysis in Feldstein (1999) by reverting to a static framework and considering the impact of non-linear amenity costs, government transfers, and full acknowledgment of the presence of amenities for the correct estimation of welfare losses from taxation. Thus, the analysis that follows is particularly useful for gaining a static viewpoint of the underlying framework that we applied earlier to a dynamic setting.

As noted at the beginning of this paper, our focus on amenities in relation to welfare and the elasticity of taxable income, although in a dynamic framework with search frictions, indeed relates directly to the static analysis in Feldstein (1999). Feldstein shows that the traditional Harberger (1964) analysis of the welfare losses from a labor income tax ignores the fact that an individual's tax liability is not exclusively a function of total labor income. Indeed, Feldstein highlights that some forms of consumption, such as mortgage interest, can be deducted by taxpayers while others, such as health benefits and pleasant working conditions, are excluded in the calculation of taxable income despite mattering for utility. Feldstein shows that in a static framework with a utility maximization problem in which taxable and non-taxable consumption and income are choice variables, the welfare losses from taxation can be stated as a function of the income tax rate, $\tau$, taxable income, $Y$, the elasticity of taxable income with respect to the net of tax rate, $\varepsilon$, and a scaling constant. Thus, Feldstein shows that in spite of the presence of itemized deductions and amenities, for example, 
understanding the welfare losses from taxation requires knowledge of only a few key variables and parameters. Importantly, however, the analysis in Feldstein (1999) assumes that the prices of leisure and untaxed compensation are fixed and omits explicit consideration of government transfers.

In order to bring to the forefront the potential relevance of substitutability between wages and amenities, we first consider the problem of a representative agent with constant elasticity of substitution utility over after-tax monetary compensation, $W$, government transfers, $T$, the fraction of time spent on leisure, $\ell \in(0,1)$, and the level of job amenities $q$, all of which we assume are choice variables. In particular, let the individual's utility be given by the constant elasticity of substitution (CES) function

$$
U=\left(\alpha(W+T)^{\sigma}+\beta \ell^{\sigma}+\gamma q^{\sigma}\right)^{1 / \sigma}
$$

where $\alpha, \beta$, and $\gamma$ are positive constants and $\sigma \in(-\infty, 1] . \sigma=1$ corresponds to the case of perfect substitutes, $\sigma=-\infty$ corresponds to perfect complements, and $\sigma=0$ is the Cobb-Douglas case. Broadly consistent with the dynamic analysis considered earlier, let a representative firm's profits be given by

$$
\pi(1-\ell)-W(1+\tau)-\phi
$$

where the first term is monetary productivity ( $\pi>0$ is exogenous), $\tau \in(0,1)$, and $\phi=\phi(q)$ is the cost of producing the amenity level $q$. In what follows, we assume $\phi^{\prime}>0$ and $\phi^{\prime \prime} \geq 0$. Since the amenity does not interact with monetary productivity, it follows that monetary productivity is not a function of the chosen amenity level.

Equilibrium $\{W, \ell, q\}$ can be interpreted as the result of workers making a take-it or leave-it offers or firms posting offers that individuals choose, in either case inducing a zero-profit condition. It follows that the representative worker's problem involves choosing a vector $\{W, \ell, q\}$ to maximize utility such that the representative firm attains at least zero profits. We assume that in solving this problem, government transfers $T$ are taken as given and therefore not necessarily related to tax payments. The framework specified above is similar to that in Feldstein (1999) except for the important distinction that we allow for the price of amenities to change according to their level.

Let $\lambda$ be the marginal value of real wealth. Then, the first-order conditions associated with the 
problem outlined above imply that

$$
\frac{\beta(\ell)^{\sigma-1}}{\pi}=\frac{\alpha(W+T)^{\sigma-1}}{1+\tau}=\frac{\gamma(q)^{\sigma-1}}{\phi^{\prime}}=\lambda .
$$

Total differentiation of the left and middle equalities implies that

$$
\frac{d \ell}{d \tau}=\kappa_{1}(1+\tau)^{1 /(1-\sigma)} \frac{d W}{d \tau}+\kappa_{1}(1+\tau)^{1 /(1-\sigma)} \frac{d T}{d \tau}+\frac{\kappa_{1}}{1-\sigma}\left(\frac{Y}{1+\tau}+T\right)
$$

while total differentiation of the middle and right equalities implies that

$$
\left(\frac{1}{1-\sigma}\left(\phi^{\prime}\right)^{\sigma /(1-\sigma)} \phi^{\prime \prime} q+\left(\phi^{\prime}\right)^{1 /(1-\sigma)}\right) \frac{d q}{d \tau}=\frac{\kappa_{1}}{\kappa_{2}} \frac{d \ell}{d \tau}
$$

where $Y=W(1+\tau)$ is taxable income, and $\kappa_{1}=(\beta /(\pi \alpha))^{1 /(1-\sigma)}$ and $\kappa_{2}=(\gamma / \alpha)^{1 /(1-\sigma)}$ are positive constants. Furthermore, note that the elasticity of taxable income with respect to the net of tax rate is

$$
\varepsilon=\frac{d \log ((1+\tau) W)}{d \log (1-\tau)} \Longrightarrow \frac{d W}{d \tau}=\frac{-Y}{(1+\tau)^{2}}-\frac{(1-\tau)^{-1} \varepsilon Y}{1+\tau}
$$

In light of the expression for $\varepsilon$, which implies that $d W / d \tau<0$, the interpretation of equation (10) is straightforward. Given a rise in taxes, $\tau$, the first term of the equation reflects a labordemand side story: all else equal, lower $W$ is consistent with lower leisure, $\ell$. The second term in the equation reflects a labor-supply side story: all else equal, if higher $\tau$ is accompanied by an increase in government transfers, then leisure rises. The third term also captures a labor-supply side story: all else equal, given higher $\tau$ workers substitute away from monetary compensation to leisure, the degree of which is increasing in the substitutability parameter $\sigma$. In turn, given a change in taxes, equation (11) relates the qualitative response of amenities to that of leisure; in particular, if $d \ell / d \tau>0$, then $d q / d \tau>0$ in which case, given equation (12), a rise in taxes is consistent with individuals substituting away from monetary compensation to leisure and non-monetary (amenity) compensation.

To see how the previous relates to the welfare losses from taxation, note that total differentiation of the utility function along with use of the first-order conditions stated in equalities (9) implies 
the following measure of the welfare change from taxation:

$$
\frac{d U}{d \tau}=\lambda\left((1+\tau)\left(\frac{d W}{d \tau}+\frac{d T}{d \tau}\right)+\pi \frac{d \ell}{d \tau}+\phi^{\prime} \frac{d q}{d \tau}\right)
$$

Several points follow.

First, suppose that $\phi^{\prime}>0$ and $\phi^{\prime \prime}=0$, which is akin to the linear cost of amenity supply assumed in Feldstein (1999), and - also in line with Feldstein's analysis - that $T=0$ and $d T / d \tau=0$. Then, it is straightforward that given equations (10), (11), and (12) the welfare change from taxation in equation (13) can be stated exclusively as a function of parameters, the proportional rate of income tax, $\tau$, taxable income, $Y$, and the elasticity of taxable income with respect to the net of tax rate, $\varepsilon .^{13}$ Under the stated assumptions, results are in line with Feldstein (1999), where, in particular, the level of amenity provision is explicitly irrelevant for correctly obtaining a measure of the welfare change from taxation. Second, note that in the event that $T>0$ and $d T / d \tau \neq 0$, then both the level and change in government transfers indeed matter for obtaining a correct measure of welfare change. Third, note that regardless of whether $T \geq 0$ and the sign of $d T / d \tau$, it is always the case that if $\phi^{\prime \prime}>0$ then the level of amenity provision becomes a key component in correctly understanding welfare changes from taxation. Thus, knowledge of the correct functional form of the cost of amenities emerges as an important factor in the correct estimation of welfare changes from taxation. Finally, note that if $d \ell / d \tau>0$, in which case as shown earlier $d q / d \tau>0$, then ignoring the existence of amenities is equivalent to ignoring the third term in equation (13), which leads to, assuming the first term in equation (13) is negative, an overstatement of the welfare losses associated with taxation. Similarly, incorrectly assuming exogenous amenity supply, $d q / d \tau=0$, also leads to such an overstatement.

While still in a static context, we end this section by considering the implications of fixed labor supply and linear utility as implemented in our earlier dynamic analysis. Consider the problem

$$
\max _{W, q} U=\alpha(W+T)+\beta \bar{\ell}+\gamma q
$$

\footnotetext{
${ }^{13}$ Recall that in the case under consideration the Lagrange multiplier can be stated as the ratio of $\alpha(Y /(1+\tau)+T)^{\sigma-1}$ to $1+\tau$.
} 
such that

$$
\pi(1-\bar{\ell})-W(1+\tau)-\phi \geq 0
$$

where, akin to the dynamic setting from earlier, labor input is assumed to be fixed at some level $1-\bar{\ell}$.

Given $\phi^{\prime}>0$ and $\phi^{\prime \prime}>0$, it is straightforward to show that

$$
\phi^{\prime}=\left(\frac{\gamma}{\alpha}\right)(1+\tau) \Longrightarrow \frac{d q}{d \tau}=\left(\frac{\gamma}{\alpha}\right) \frac{1}{\phi^{\prime \prime}}
$$

meaning that the optimal level of $q$ is only a function of parameters and taxes, and furthermore that $d q / d \tau$ is unambiguously positive. Also, note that a measure of the welfare change from taxation is simply

$$
d U / d \tau=(d W / d \tau+d T / d \tau)+d q / d \tau .
$$

Once again using equation (12) to substitute for $d W / d \tau$, conclusions similar to those in the previous setting of CES utility follow. First, the welfare change from taxation can be stated as a function of parameters, the proportional rate of income tax, $\tau$, taxable income, $Y$, and the elasticity of taxable income with respect to the net of tax rate, $\varepsilon$. Second, the level of the amenity matters for the correct estimation of the welfare change from taxation, as do changes in transfers - or, in other words, the transfer scheme. Third, if the first term in equation (17) is negative, then ignoring the existence of the amenity or incorrectly assuming that it is determined exogenously implies an overstatement of welfare losses from taxation. Thus, results are broadly in line with those stemming under the assumption of curvature in the utility function. ${ }^{14}$

In order to obtain a quantitative perspective of the overestimation of the welfare impact of taxation, we solve the model numerically under the assumption that the government runs a balanced budget, implying that transfers are given by $T=\tau \cdot W$. We conduct this exercise both for the case in which amenities are either ignored or thought to be exogenous, and the case in which the amenity cost function is misspecified. In both cases, CES utility is assumed, which allows us to generically find interior solutions and evaluate the range of possibilities for substitution between

\footnotetext{
${ }^{14}$ Of course, if instead $\phi^{\prime \prime}=0$ then the solution to the (linear) utility maximization problem involves the possibility of both interior and corner solutions, all of which are straightforward to derive, but with much less rich implications for the estimation of the welfare effects of taxation. Thus, we omit explicit consideration of this case.
} 
amenity and ordinary consumption. For simplicity, we assume that the preference for consumption

$\alpha$, the preference for leisure $\beta$, and the preference for the amenity are all equal to $1 / 3$. The true amenity cost function is assumed to be $c(q)=(1 / A) \exp (q)$. In order to stay on the left side of the Laffer curve, only calibrations that imply $d T / d \tau \geq 0$ are discussed: this imposes restrictions on the efficiency of amenity production and monetary productivity, which are consequently set to 1 and 2 , respectively. In addition, we consider cases for reasonable values of the overall wage tax rate in the United States and for various values of the elasticity of substitution, $\sigma$.

Table 5 shows results. Define the deadweight loss from taxation (DWL) by $-d U / d \tau$. The extent of DWL overestimation from ignorance of the amenity is presented in Table 5's second-tolast column as the ratio of the DWL believed to be true, which stems from incorrectly assuming amenities, to the true deadweight loss. The final column of Table 5 shows the analogous measure of DWL overestimation in the case of an econometrician who incorrectly assumes that amenity costs are linear when in fact they are convex as noted earlier. For reasonable values of the overall wage tax rate in the United States, ignorance of amenity supply induces an overestimation of deadweight loss that is very sizable: DWL is believed to be about 2 to 4 times larger than it actually is when amenities are incorrectly assumed to be exogenous, and 1.3 to 1.8 times larger when the amenity cost function is incorrectly assumed to be linear. Moreover, overestimation is an increasing function of the elasticity of substitution $\sigma$, as one would expect: the more substitutable amenities are with wages and leisure, the larger is the miscalculation of an econometrician who assumes amenities to be exogenous.

\section{$5 \quad$ Related Literature}

Three important papers inform our structural analysis: Mortensen and Pissarides (1994) (job search), Jovanovic (1979) (job duration as match quality), and Shimer (2006) (on-the-job search). Mortensen and Pissarides provide the basic framework for the random search model employed in this paper, albeit without on-the-job search and other modifications. Working within the Mortensen and Pissarides class of model, Shimer (2006) adds on-the-job search in a partial equilibrium context, with job offers arriving at an exogenous rate constrained to be the same on and off the job.

By embedding match quality variation in an equilibrium model of job turnover, Jovanovic 
(1979) and related papers like McCall (1990) provide a theoretical basis for an assertion we exploit in this paper, which is that tenure is informative about job match quality. Indeed, a large, mostly empirical literature has developed that takes tenure as a proxy for match quality and examines, for example, job mismatch over the business cycle (Bowlus, 1995, Kahn, 2008) and the effects of changes in unemployment insurance law (Ours and Vodopivec, 2008). Some authors have pursued related questions with identification or calibration strategies making use of duration data. Nagypal (2007), for instance, distinguishes accumulation of human capital from learning about match quality using, in part, matched firm-worker data including tenure information. Becker (2009) focuses on job amenities and finds that they are quantitatively substantial.

Sullivan and To (2011) assess the relative importance of wage and non-wage job utility. They estimate the offer distributions of wages and non-wage utility in a search context, and use the fraction of job switches associated with wage declines to identify the distribution of non-wage utility. Although they are not concerned with estimating the distribution of match quality, like Becker (2009), Sullivan and To find non-wage utility to be substantial.

Though the present paper is not explicitly about compensating differentials, separate estimation of productivity and amenities along with the particular wage bargain assumed implicitly involve tradeoffs between wages and amenities. As is intuitively the case, workers in jobs with low amenities will (holding match quality constant) receive higher wages. Our framework makes use of wages to help separate productivity and amenities, which puts it in debt of papers like Rosen (1974) and Friedman and Kuznets (1954). Unlike most compensating differentials papers, however, the present paper does not assume equality of utility across options and the focus is on parameters of the aggregate match quality distributions rather than cross-sectional tradeoffs.

On-the-job search models typically predict that all job changes will be associated with increases in observed wages. However, this is decidedly not the case in the data ${ }^{15}$, and various solutions have been proposed. Of course, some or all of wage declines associated with job-to-job transitions can be interpreted as measurement error. In the NLSY79, for instance, that some reported wage declines are spurious is explicitly noted by the survey administrators. ${ }^{16}$ Wolpin (1987) and related literature

\footnotetext{
${ }^{15}$ See Sullivan and To (2011) for data from the NLSY97. Postel-Vinay and Robin (2002) find a similar result in French data, with a third to a half of workers reporting wage decreases as they change jobs.

${ }^{16}$ From NLSY79 documentation at http://www.nlsinfo.org/nlsy79/docs/79html/79text/wages.htm: "Note that: the calculation procedure, which factors in each respondent's usual wage, time unit of pay, and usual hours worked per day/per week produces, at times, extremely low and extremely high pay rate values; no editing of values
} 
explicitly incorporate measurement error into their models. It is difficult to explain the extent of job-to-job transitions that involve wage declines with measurement error alone, considering, for instance, that a full third of job-to-job wage changes in the NLSY79 are reductions. Another approach is to construct some aspect of the model that leads workers to (occasionally) optimally switch to lower-wage jobs. As an example, Postel-Vinay and Robin (2002) and Cahuc et al. (2006) use a bargaining arrangement that allows workers to choose lower-wage but higher-productivity firms that will in the future be able to better match outside offers. The present paper, though not principally motivated by the concern of wage reductions in job-to-job transitions, provides a different answer to this question. When unpriced amenities are accounted for, optimal wage choice is such that workers will frequently choose lower-wage jobs that are nonetheless preferred to previous jobs due to their superior amenities.

\section{Conclusion}

The costly, endogenous supply of job amenities by firms has a number of interesting implications for labor markets and public policy. Work by Martin Feldstein and others has made the case for utilizing data on taxable income elasticities, rather than labor supply elasticities, for the purpose of calculating social welfare consequences of taxation. We show that it is necessary to estimate the heterogeneity and parameters of amenity supply in order to correctly infer deadweight loss from taxation.

Furthermore, our analysis implies that deadweight loss from taxation is generally overestimated if explicit consideration of amenities is omitted. In illustrative calibrations, this overestimation is shown to be proportional to the quantitative significance of heterogeneity in amenities across job matches. Additionally, the endogenous supply of amenities is shown to exacerbate this overestimation. Finally, we argue that long-run taxable income elasticities, while often considered by the public finance literature to be preferable, can be even more misleading than short-run elasticities after taking into account the possibility of gradual migration of workers into more amenity-focused job matches in response to tax increases.

reported by a respondent occurs even if the value is extreme, such as $\$ 25,000$ per hour..." 


\section{References}

BECKER, D. (2009): "Non-wage job characteristics and the case of the missing margin," Working paper.

Blackwell, D. (1965): "Discounted dynamic programming," The Annals of Mathematical Statistics, 36, 226-235.

Bowlus, A. (1995): "Matching workers and jobs: cyclical fluctuations in match quality," Journal of Labor Economics, 13, no. 2, 335-50.

Cahuc, P., F. Postel-Vinay, And J.-M. Robin (2006): "Wage bargaining with on-the-job search: theory and evidence," Econometrica, 74, 323-64.

Chetty, R. (2008): "Is the taxable income elasticity sufficient to calculate deadweight loss? The implications of evasion and avoidance," NBER, 13844.

Chetty, R., J. N. Friedman, T. Olsen, and L. Pistaferri (2011): “Adjustment costs, firm responses, and micro vs. macro labor supply elasticities: evidence from Danish tax records," NBER Working Paper, No. 15617.

Epstein, B. And M. S. Kimball (2011): "The Decline of Drudgery and the Paradox of Hard Work," Working paper.

Feldstein, M. (1999): "Tax avoidance and the deadweight loss of the income tax," The Review of Economics and Statistics, 81, 674-80.

Friedman, M. And S. Kuznets (1954): Income from Independent Professional Practice, NBER.

HALl, R. (2005): "Employment efficiency and sticky wages: evidence from flows in the labor market," NBER Working Paper, 11183.

Harberger, A. (1964): "The measurement of waste," The American Economic Review, 54 (3), $58-76$.

Jovanovic, B. (1979): "Job matching and the theory of turnover," The Journal of Political Economy, 87, No. 5, 972-90. 
KAHN, L. (2008): "Job durations, match quality and the business cycle: what we can learn from firm fixed effects," Working paper.

MCCAll, B. (1990): "Occupational matching: a test of sorts," Journal of Political Economy, 98, $45-69$.

Mortensen, D. And C. Pissarides (1994): "Job creation and job destruction in the theory of unemployment," The Review of Economic Studies, 61, no. 3, 397-415.

NAGYPAL, E. (2007): "Learning by doing vs. learning about match quality: can we tell them apart?" The Review of Economic Studies, 74, 537-66.

- (2008): "Worker reallocation over the business cycle: the importance of job-to-job transitions," Working paper.

Nunn, R. (2012): "Match quality with unpriced amenities," Working paper.

OECD (2012): OECD Revenue Statistics.

Ours, J. V. And M. Vodopivec (2008): "Does reducing unemployment insurance generosity reduce job match quality?" Journal of Public Economics, 92, 684-95.

Postel-Vinay, F. And J.-M. Robin (2002): "Equilibrium wage dispersion with worker and employer heterogeneity," Econometrica Vol.70 No.6, 2295-350, 70, 2295-350.

Rosen, S. (1974): "Hedonic prices and implicit markets: product differentiation in pure competition," Journal of Political Economy, 82, 34-55.

(1986): The theory of equalizing differences, Elsevier.

Saez, E., J. Slemrod, And S. Giertz (2009): "The elasticity of taxable income with respect to marginal tax rates: a critical review," NBER Working Paper, 15012.

Sargent, T. (1987): Dynamic macroeconomic theory, Harvard University Press.

Shimer, R. (2003): "Dynamics in a model of on-the-job search," Working paper.

- (2006): "On-the-job search and strategic bargaining," European Economic Review, 50, 81130. 
Sullivan, P. And T. To (2011): "Search and non-wage job characteristics," Working paper.

TAuchen, G. (1986): "Finite state markov chain approximations to univariate and vector autoregressions," Economic Letters, 20, 177-81.

WolPiN, K. (1987): "Estimating a structural search model: the transition from school to work," Econometrica, 55, 801-17. 


\section{Table 1: Summary statistics (NLSY79)}

\begin{tabular}{ll}
\hline \hline Age & 29.5 (mean) \\
Education & 12.6 years (mean) \\
Race & \\
Black & $13.1 \%$ \\
Hispanic & $7.6 \%$ \\
Else & $79.3 \%$ \\
Sex & \\
Female & $49.7 \%$ \\
Male & $50.3 \%$ \\
Tenure & 30.2 months (mean) \\
Wage & $\$ 15.8 /$ hour (mean) \\
\hline
\end{tabular}

Notes: Observations associated with the military and supplemental subsamples, as well as currentlyenrolled high-school and college students, are dropped. 


\section{Table 2: Simulated and empirical (NLSY79) moments}

\begin{tabular}{lcc}
\hline \hline \multicolumn{1}{c}{ Moments } & Simulated & Empirical target \\
\hline Mean tenure & 32.2 & 30.5 \\
Variance of tenure & 1419 & 1419 \\
Skewness of tenure & 2.32 & 2.29 \\
Unemployment benefits as a fraction of flow output & 0.332 & 0.500 \\
Unemployment rate & 0.041 & 0.046 \\
Job-to-job transition probability & 0.013 & 0.014 \\
Unemployment-to-employment transition probability & 0.248 & 0.193 \\
Wage-tenure correlation & 0.225 & 0.225 \\
Wage coefficient of variation & 0.409 & 0.489 \\
\hline
\end{tabular}

Notes: all moments are at a monthly frequency. Observations associated with the military and supplemental subsamples, as well as currently-enrolled high-school and college students, are dropped. The empirical tenure distribution and transition probabilities are generated according to a procedure described in the text. 


\section{Table 3: Effects of wage taxation}

\begin{tabular}{|c|c|c|c|c|c|c|c|c|}
\hline \multirow[b]{2}{*}{ Tax rate } & \multicolumn{4}{|c|}{ Endogenous amenities } & \multicolumn{4}{|c|}{ Exogenous amenities (Nunn 2012) } \\
\hline & $\begin{array}{c}\text { Social } \\
\text { welfare }\end{array}$ & $\begin{array}{l}\text { Taxable } \\
\text { income }\end{array}$ & $\begin{array}{c}\text { Social } \\
\text { welfare } \\
\text { elasticity }\end{array}$ & $\begin{array}{l}\text { Taxable } \\
\text { income } \\
\text { elasticity }\end{array}$ & $\begin{array}{l}\text { Social } \\
\text { welfare }\end{array}$ & $\begin{array}{l}\text { Taxable } \\
\text { income }\end{array}$ & $\begin{array}{c}\text { Social } \\
\text { welfare } \\
\text { elasticity }\end{array}$ & $\begin{array}{l}\text { Taxable } \\
\text { income } \\
\text { elasticity }\end{array}$ \\
\hline $0 \%$ & 100.0 & 100.0 & - & - & 100.0 & 100.0 & - & - \\
\hline $10 \%$ & 99.6 & 92.7 & 0.04 & 0.72 & 99.7 & 95.5 & 0.03 & 0.44 \\
\hline $20 \%$ & 99.0 & 88.1 & 0.05 & 0.43 & 99.1 & 93.5 & 0.05 & 0.18 \\
\hline $30 \%$ & 97.8 & 84.2 & 0.09 & 0.34 & 98.2 & 91.9 & 0.07 & 0.13 \\
\hline $40 \%$ & 96.1 & 79.5 & 0.11 & 0.37 & 96.9 & 90.4 & 0.09 & 0.11 \\
\hline $50 \%$ & 92.9 & 71.0 & 0.19 & 0.62 & 95.0 & 87.5 & 0.11 & 0.18 \\
\hline $60 \%$ & 86.9 & 55.0 & 0.30 & 1.14 & 89.9 & 77.9 & 0.25 & 0.52 \\
\hline $70 \%$ & 77.5 & 32.6 & 0.40 & 1.82 & 83.3 & 67.7 & 0.27 & 0.49 \\
\hline $80 \%$ & 59.7 & - & - & - & 72.2 & 50.3 & 0.35 & 0.73 \\
\hline $90 \%$ & 21.9 & - & - & - & 49.8 & 15.9 & 0.54 & 1.66 \\
\hline
\end{tabular}

Notes: Social welfare and taxable income are indexed to 100 at a $0 \%$ tax rate and defined as described in the text. Elasticities are calculated by the comparison of steady-state equilibria and are taken with respect to the net-of-tax rate. Analysis uses data from the NLSY79 as detailed in the text. For the endogenous amenities environment, taxable income falls below zero when the tax rate rises above $70 \%$, in which case results are omitted. 
Table 4: Impact over time of wage taxation

\begin{tabular}{ccc}
\hline \hline Month & $\begin{array}{c}\text { Social } \\
\text { welfare }\end{array}$ & $\begin{array}{c}\text { Taxable } \\
\text { income }\end{array}$ \\
\hline 0 & 100.0 & 100.0 \\
1 & 98.2 & 99.1 \\
6 & 97.6 & 98.5 \\
12 & 97.7 & 98.0 \\
18 & 97.7 & 97.4 \\
24 & 98.0 & 97.6 \\
30 & 98.4 & 97.6 \\
36 & 97.9 & 97.4 \\
42 & 98.1 & 97.3 \\
48 & 97.9 & 97.0 \\
\hline
\end{tabular}

Notes: Social welfare and taxable income are indexed to 100 at an initial assumed 24.8 percent tax rate (see text for details). In month 1 an unexpected and permanent increase in taxes of 10 percentage points occurs. 
Table 5: Static-economy results

\begin{tabular}{cc|cc|cc}
\hline \hline \multicolumn{2}{c|}{ Parameters } & \multicolumn{2}{c|}{ Variables } & \multicolumn{2}{c}{ DWL } \\
Substitutability & Tax rate & Amenities & Labor & \multicolumn{2}{c}{ overestimation } \\
$\sigma$ & $\tau$ & $q$ & $l$ & $(\mathrm{~A})$ & $(\mathrm{B})$ \\
\hline-0.5 & 0.15 & 0.267 & 0.201 & 3.90 & 1.68 \\
$"$ & 0.25 & 0.271 & 0.204 & 2.72 & 1.41 \\
$"$ & 0.35 & 0.274 & 0.207 & 2.22 & 1.29 \\
0.001 & 0.15 & 0.276 & 0.182 & 3.97 & 1.72 \\
$"$ & 0.25 & 0.282 & 0.187 & 2.76 & 1.43 \\
$"$ & 0.35 & 0.287 & 0.191 & 2.25 & 1.31 \\
0.5 & 0.15 & 0.293 & 0.131 & 4.25 & 1.82 \\
$"$ & 0.25 & 0.306 & 0.141 & 2.92 & 1.50 \\
$"$ & 0.35 & 0.317 & 0.149 & 2.35 & 1.37 \\
\hline
\end{tabular}

Notes: The overestimation of the deadweight loss from taxation (DWL) is calculated as the ratio of the DWL believed to be correct to the true deadweight loss. See text for details. Panel (A) presents the case in which amenities are endogenous with convex supply cost, but incorrectly assumed to be exogenous. Panel (B) presents the case in which amenities are endogenous with convex supply cost, but incorrectly assumed to be subject to a linear production cost. 
Figure 1: Unweighted empirical tenure distribution (NLSY79)

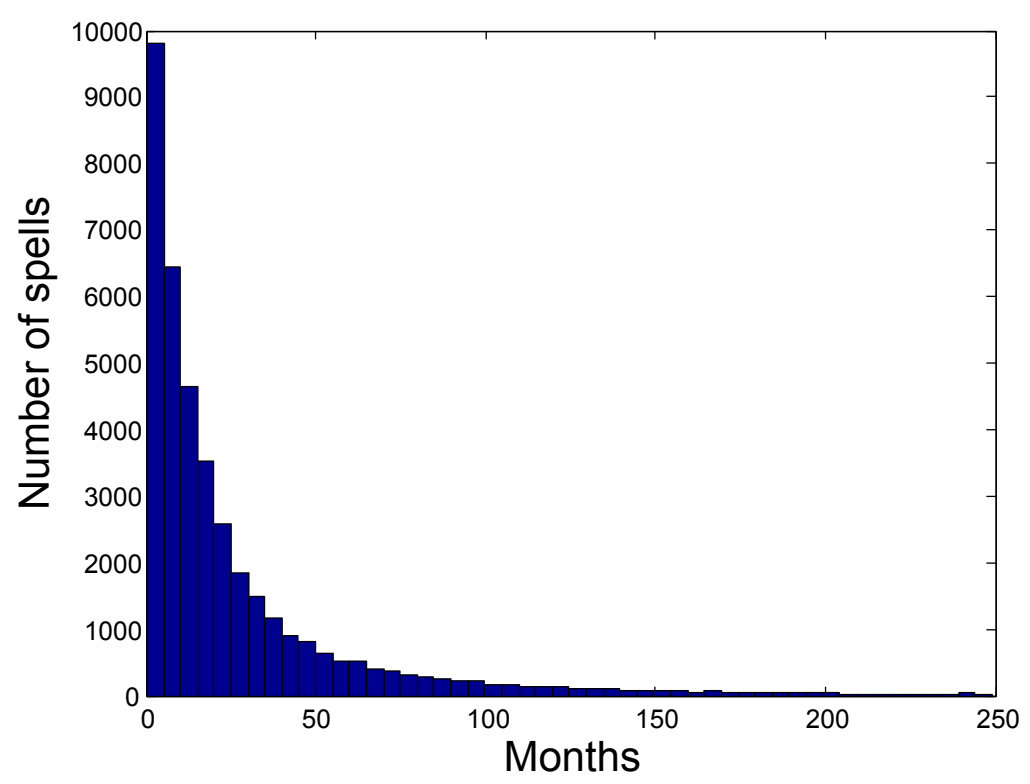

Notes: spells are defined as uninterrupted periods of employment at a particular job. Observations associated with the military and supplemental subsamples, as well as currently-enrolled high-school and college students, are dropped. 